\title{
Annotation
}

Archives of Disease in Childhood, 1976, 51, 161.

\section{CPAP or not CPAP?}

In the past 5 years there has been a considerable increase in the survival rate of infants suffering from the idiopathic respiratory distress syndrome (RDS) (Roberton and Tizard, 1975). Though considerable changes in treatment have occurred during this period, many workers attribute a large part of the fall in mortality to the technique of continuous positive airways pressure (CPAP, or continuous distending pressure-CDP, or continuous inflating pressure-CIP) first described in 1971 (Gregory et al., 1971).

The effects of CPAP on lung function are complex (Bancalari, Garcia, and Jesse, 1973), but in animals it minimizes surfactant consumption (Wyszogrodski et al., 1975), and from a practical point of view there can be no doubt that it improves the pattern and regularity of respiration (Spiedel and Dunn, 1975) and virtually always improves arterial oxygenation in infants with RDS (Baum and Roberton, 1974). However, the technique is not without its hazards. The incidence of pneumothorax may be at least three times higher in infants receiving CPAP and thus undoubtedly worsens their prognosis (Yu, Liew, and Roberton, 1975). Sudden deterioration of the infant may occur during the manipulation required to initiate CPAP (Roberton and Tizard, 1975). Other complications described are intraventricular haemorrhage (Vert, Andre, and Sibout, 1973), excoriation of the neck by the seal of a CPAP headbox (Krauss and Marshall, 1975), and brachial plexus palsy from the same apparatus (Turner, Evans, and Brown, 1975). There are also the hazards specifically associated with endotracheal tubes when these are used to apply CPAP. If CPAP is applied by face mask (Rhodes and Hall, 1973) or nasal prongs (Kattwinkel et al., 1973), which can be set up with minimal disturbance to the infant, many of these complications can be avoided.

Despite these problems, only two controlled trials of CPAP have been reported in full. Rhodes and Hall (1973) showed a small but significant improvement in mortality only in infants weighing more than $1500 \mathrm{~g}$ at birth. Fanaroff et al. (1973), though showing improved oxygenation and shorter duration of oxygen therapy, showed no improvement in mortality in their treated group. Both this study and two other controlled studies reported in abstract only (Krouskop, Brown and Sweet, 1974; Mockrin and Bancalari, 1974), showed that CPAP, particularly if started early, considerably shortened the course of the illness and the duration of oxygen therapy, and minimized the need for intermittent positive pressure ventilation (IPPV).

It is intuitively obvious that any technique which shortens the illness in infants with RDS, and minimizes their exposure to high inspired oxygen concentration and to IPPV, must improve their chances of survival, and many workers attribute the improvement in mortality from RDS in their units to CPAP (Dunn, 1974). Chernick (1973) felt able to write, 'one or two controlled trials in the use of constant distending pressure in severe hyaline membrane disease, although daring, are welcome; many more would be foolish'.

On page 163, Durbin and his co-authors (1976) from University College Hospital, having ignored Chernick's advice, come up with what now seems to be the standard answer from controlled trials of CPAP - that it makes no difference to mortality, but does shorten the duration of exposure to high oxygen concentration, though in their study it did not reduce the number of infants requiring IPPV.

Why do the controlled studies of CPAP fail to show an improvement in mortality from RDS when there is such a body of opinion that it has saved the lives of many infants with this condition? In the UCH study it could in part be due to their starting CPAP late in the course of the illness. This was no doubt forced on them by the large number of infants in their nursery referred from outside hospitals. If a major benefit of CPAP is to minimize surfactant destruction early in the course of RDS (Farrell and Avery, 1975), the later it is started, the less likely it is to be of great benefit to the infant. However, as Durbin et al. point out, even starting CPAP much earlier in their study would at best have resulted in a $5 \%$ decrease in the mortality from RDS. Yet looked at the other way this means approximately halving the mortality! ( $88 \%$ survival to $93 \%$ survival $=12 \%$ mortality to $7 \%$ mortality.)

The major reason for the failure of controlled trials of CPAP to show a significant fall in the RDS mortality must be that they have been carried out in intensive care units whose staff not only are experienced with CPAP, but who are very com- 
petent in the use of IPPV. The record of UCH in this respect is outstanding. In a series of studies summarized by Reynolds (1975) in his article in the British Medical Bulletin last year, he and his co-workers have shown that with the use of the Draeger Ventilator, at a slow rate, long I : E ratio, with some positive end-expiratory pressure, they can achieve a very high level of success using IPPV in RDS. In $\mathrm{UCH}$, as in the other units reporting controlled studies, when CPAP fails they can bale themselves out by skilled use of the ventilator. In other units less well endowed with ventilators, monitoring equipment, residents, and nursing staff (particularly at night), rescue by IPPV will not be possible.

The Durbin paper, like all the others reporting controlled trials, still leaves the two most difficult questions unanswered. When is the best time to start CPAP in terms of both the infant's age and oxygen requirements? And in what type of intensive care nursery can it safely be applied? To wait until the infant requires an $\mathrm{F}_{1} \mathrm{O}_{2}$ of 0.95 to keep his $\mathrm{PaO}_{2} 60$ torr, is clearly cavalier, unless one can ventilate infants as well as Durbin and his colleagues. To start at lower inspired oxygen concentrations, say an $\mathrm{F}_{\mathrm{I}} \mathrm{O}_{2}$ of 0.4 to keep the $\mathrm{PaO}_{2}$ 60 torr is one possible approach, since the infant is then likely to be treated early in the course of the disease, and is most likely to benefit from surfactant conservation, and shortening of the illness. However, this recommendation would mean treating many more infants than at present, and would overstretch the facilities in many smaller units since CPAP should only be applied if there are adequate facilities for heart rate and blood pressure monitoring, 24-hour resident cover, and blood gas analysis facilities.

Until unequivocal benefits are shown in a controlled trial from starting CPAP at such a low $\mathrm{F}_{\mathrm{I}} \mathrm{O}_{2}$, and that the benefits of starting at this level outweigh the potential hazards of CPAP, it seems justifiable to recommend that infants with RDS should initially be managed conservatively by measuring arterial blood gases and adjusting the $\mathrm{F}_{\mathrm{x}} \mathrm{O}_{2}$ to keep the $\mathrm{PaO}_{2}$ in the range 60-90 torr. Once the $\mathrm{F}_{\mathrm{x}} \mathrm{O}_{2}$ has to be increased to $0.55-0.60$ to sustain $\mathrm{a} \mathrm{PaO}_{2}$ of 60 torr, CPAP should be instituted. Since about $20 \%$ of such infants will develop a pneumothorax once on CPAP, and another 30\% will need a period of IPPV, CPAP should only be applied in appropriately equipped nurseries. If such facilities are not available, the infant should be transferred at once, while he is still in reasonable condition and only requiring $\mathrm{FO}_{\mathrm{I}_{2}}$ of 0.6 , to a regional neonatal intensive care centre. At such a centre the modern techniques of neonatal intensive care are such that no infant with RDS should die of respiratory failure even if a prolonged period of IPPV is required.

The major benefit from CPAP may well turn out to be not that more infants get better, but that they get better faster.

\section{N. R. C. ROBERTON \\ Department of Paediatrics, Addenbrooke's Hospital, Hills Road, Cambridge CB22QQ.}

REFERENCES

Bancalari, E., Garcia, O. L., and Jesse, M. J. (1973). Effects of continuous negative pressure on lung mechanics in idiopathic respiratory distress syndrome. Pediatrics, 51, 485.

Baum, J. D., and Roberton, N. R. C. (1974). Distending pressure in infants with respiratory distress syndrome. Archives of Disease in Childhood, 49, 771.

Chernick, V. (1973). Continuous distending pressure in hyaline membrane disease. Pediatrics, 52, 114.

Dunn, P. M. (1974). Continuous positive airway pressure, using the Gregory box. Proceedings of Royal Society of Medicine, 67, 245.

Durbin, G. M., Hunter, N. J., McIntosh, N., Reynolds, E. O. R., and Wimberley, P. D. (1976). Controlled trial of continuous inflating pressure for hyaline membrane disease. Archives of Disease in Childhood, 51, 163.

Fanaroff, A. A., Cha, C. C., Sosa, R., Crumrine, R. S., and Klaus, M. H. (1973). Controlled trial of continuous negative external pressure in the treatment of severe respiratory distress syndrome. Fournal of Pediatrics, 82, 921.

Farrell, P. M., and Avery, M. E. (1975). Hyaline membrane disease. American Review of Respiratory Diseases, 111, 657.

Gregory, G. A., Kitterman, J. A., Phibbs, R. H., Tooley, W. H., and Hamilton, W. K. (1971). Treatment of idiopathic respiratory distress syndrome with continuous positive airway pressure. New England fournal of Medicine, 284, 1333.

Kattwinkel, J., Fleming, D., Cha, C. C., Fanaroff, A. A., and Klaus, M. H. (1973). A device for administration of continuous positive airway pressure by the nasal route. Pediatrics, 52, 131 .

Krauss, D. R., and Marshall, R. E. (1975). Severe neck ulceration from CPAP head box. Fournal of Pediatrics, 86, 286.

Krouskop, R. W., Brown, E. G., and Sweet, A. Y. (1974). The early use of continuous positive airway pressure (CPAP) in hyaline membrane disease. Pediatric Research, 8, 448.

Mockrin, L., and Bancalari, E. (1974). Continuous negative pressure in hyaline membrane disease: early versus late onset. Pediatric Research, 8, 448.

Reynolds, E. O. R. (1975). Management of hyaline membrane disease. British Medical Bulletin, 31, 18.

Rhodes, P. G., and Hall, R. T. (1973). Continuous positive airway pressure delivered by face mask in infants with the idiopathic respiratory distress syndrome. A controlled study. Pediatrics, $52,1$.

Roberton, N. R. C., and Tizard, J. P. M. (1975). Prognosis for infants with idiopathic respiratory distress syndrome. British Medical Fournal, 3, 271.

Speidel, B. D., and Dunn, P. M. (1975). Effect of continuous positive airway pressure on breathing pattern of infants with respiratory-distress syndrome. Lancet, 1, 302.

Turner, T., Evans, J., and Brown, J. K. (1975). Monoparesis: complication of constant positive airways pressure. Archives of Disease in Childhood, 50, 128.

Vert, P., Andre, M., and Sibout, M. (1973). Continuous positive airway pressure and hydrocephalus. Lancet, 2, 319.

Wyszogrodski, I., Kyei-Aboagye, K., Taeusch, H. W., and Avery, M. E. (1975). Surfactant inactivation by hyperventilation; conservation by end expiratory pressure. Fournal of Applied Physiology, 38, 461.

Yu, V. Y. H., Liew, S. W., and Roberton, N. R. C. (1975). Pneumothorax in the newborn. Archives of Disease in Childhood. 50 449. 